\title{
Hypnosis and Dyspareunia: A Meta Analysis
}

\author{
Ratna Dewi Kumalasari' ${ }^{\text {1) }}$, Didik Gunawan Tamtomo²), Hanung Prasetya' \\ 1)MastersProgram in Public Health, Universitas Sebelas Maret \\ ${ }^{2}$ Department of Anatomy, Facultyof Medicine, Universitas Sebelas Maret
}

\section{ABSTRACT}

Background: Sexual satisfaction refers to a person's pleasant feelings from the type of sexual relationship that forms an important part of one partner's impression of another. $75 \%$ of women experience sexual problems. Symptoms of sexual dysfunction occur in nearly half of the marriage period and $75 \%$ of couples need therapy. This study aims to analyze the effect of hypnosis on pain during sexual activity and the intensity of pain.

Subjects and Method: This study was a meta-analysis and a systematic study. The articles used were obtained from several electronic databases including Pubmed, Science Direct, Springer Link, and Google Scholar. Articles were collected for 4 weeks. The keywords to search for articles were as follows: "non-medical therapy", "non-medical care", "randomized control trial", "sexual disturbance", "sexual function", "sexual satisfaction". The articles studied were full text articles with an observational research design. Articles were collected using PRISMA diagrams, and analyzed using the Review Manager 5.3 application.

Results: The effects of hypnosis on pain during sexual activity $(\mathrm{aOR}=3.55 ; 95 \% \mathrm{CI}=$ 2.63 to $4.79 ; \mathrm{p}=0.001$ ) and intensity of pain $(\mathrm{aOR}=2.39 ; 95 \% \mathrm{CI}=1.96$ to $2.82 ; \mathrm{p}=0.006)$.

Conclusion: Hypnosis can reduce pain during sexual activity and the intensity of pain.

Keywords: Hypnosis, sexual dysfunction

\section{Correspondence:}

Kumalasari. Masters Program in Public Health Sciences, Universitas Sebelas Maret, Jl. Ir. Sutami 36A, Surakarta 57126, Central Java. Email: logicakinanthi@gmail.com. Mobile: +62812623900900.

\section{Cite this as:}

Kumalasari RD, Tamtomo DG, Hanung H (2020). Hypnosis and Dyspareunia: A Meta Analysis. Indones J Med. 05(04): 291-298. https://doi.org/10.26911/theijmed.2020.05.04.04. (c) (i) (2) I Indonesian Journal of Medicine is licensed under a Creative Commons

\section{BACKGROUND}

Sexual dysfunction is a problem in achieving satisfaction in sexual activity. Most women think that the happiness of life is the satisfaction in marriage compared to work, friendship, hobbies, and activities (Andromeda and Noviajati, 2015). Sexuality is not always focused on coital activities which include cycles of desire, excitement, orgasm, and resolution but is also associated with non-coital activities. This aspect can be manifested in the form of seeing and talking intimately with a partner, holding hands, caring, kissing, and having fun in a relationship with a partner (Harvey et al., 2004; Breslin and Lucas, 2003).

Sexual satisfaction refers to a person's pleasurable feelings from this type of sexual relationship which forms an important part of one partner's impression of another which in turn maintains their marriage. Masters, Johnson, and Kaplan were the first researchers to conduct a systematic literature study relating to human sexual behavior. The preliminary researchers considered the four sexual attributes as (desire) namely arousal, plateau, orgasm, and resolution; then another study identified the six 
sexual functions of women namely desire, arousal, wetness, orgasm, satisfaction, and pain (Vaziri et al., 2010).

Halvorsen and Metz (1991) stated that $75 \%$ of all women and $50 \%$ of all men have experienced sexual difficulties. Sexual dysfunction occurs in nearly half of marriages and about $75 \%$ of couples need therapy or assistance with marital problems. Most of the hidden sexual problems, medical personnel who are competent in their field must understand how to approach the diagnosis correctly, evaluate it based on history, physical examination, and perform laboratory tests. Furthermore, the doctor must understand how to initiate the management of this problem, arrange the necessary actions, and know the scheduling required along with consultation and referral from experts or professionals for issues that are beyond their expertise or interest. Based on the background of this study, the question arised is "Is There Any Effect of Hypnosis on Sexual Dysfunction Disorders?".

\section{SUBJECTS AND METHOD}

\section{Study Design}

This was ameta-analysis study. The study was carried out by collecting published articles from year 2000 to 2020, from Pubmed, Science Direct, Springer Link, and Google Scholar databases.

Key words used include: "hypnotherapy" "hypnosis" "non-medical therapy", "non-medical care", "randomized control trial", "sexual disturbance", "sexual function", "sexual satisfaction".

\section{Population and Sample}

The articles selected in this study were studies published in the 2000-2020. The selected article discusses the application of hypnosis in women with sexual dysfunction disorders, especially disorders of sexual arousal. The articles used is in English. The study samples were women with com- plaints of sexual dysfunction. The final results of the study were reported using the adjusted odds ratio (aOR).

\section{Inclusion and Exclusion Criteria}

The exclusion criteria in this study were articles that did not use a randomized control trial (RCT). Articles that used hypnosis which were not as a primary treatment also included the exclusion criteria in this study.

\section{Operational Definition of Variables} Sexual Dysfunction Disordersrefers to problems that occur during the phase of the sexual response cycle that prevent a person or partner from experiencing satisfying in sexual activity.

Pain during sexual activity refers to pain during or after sexual activity, either in the vagina or deeper in the pelvis. Vaginal pain can be caused by: sexually transmitted disease (STDs), such as chlamydia, gonorrhea, or genital herpes. It can also be caused by hormonal changes during menopause, which make the vagina dry.

Pain intensity or the amount of pain experienced is a narrow construct that often measured using a 1-item scale.

Hypnosis can be interpreted as a mental unconscious state (trance) in which a person experiences increased attention, concentration, and suggestibility.

\section{Data Analysis}

Meta-analysis with fixed effects models assumes that the study being modeled is homogeneous. Therefore, there were no differences in the study population, there was no differences in patient selection criteria that might affect the outcome of therapy, and the therapy was performed in the same way. In this model, the component of the variance between studies was ignored, only variance within the study.

\section{RESULTS}

The process of finding articles using a journal database is shown in Figure 1. The arti- 
cles in this study come from two continents, namely America (Canada, 1 study;

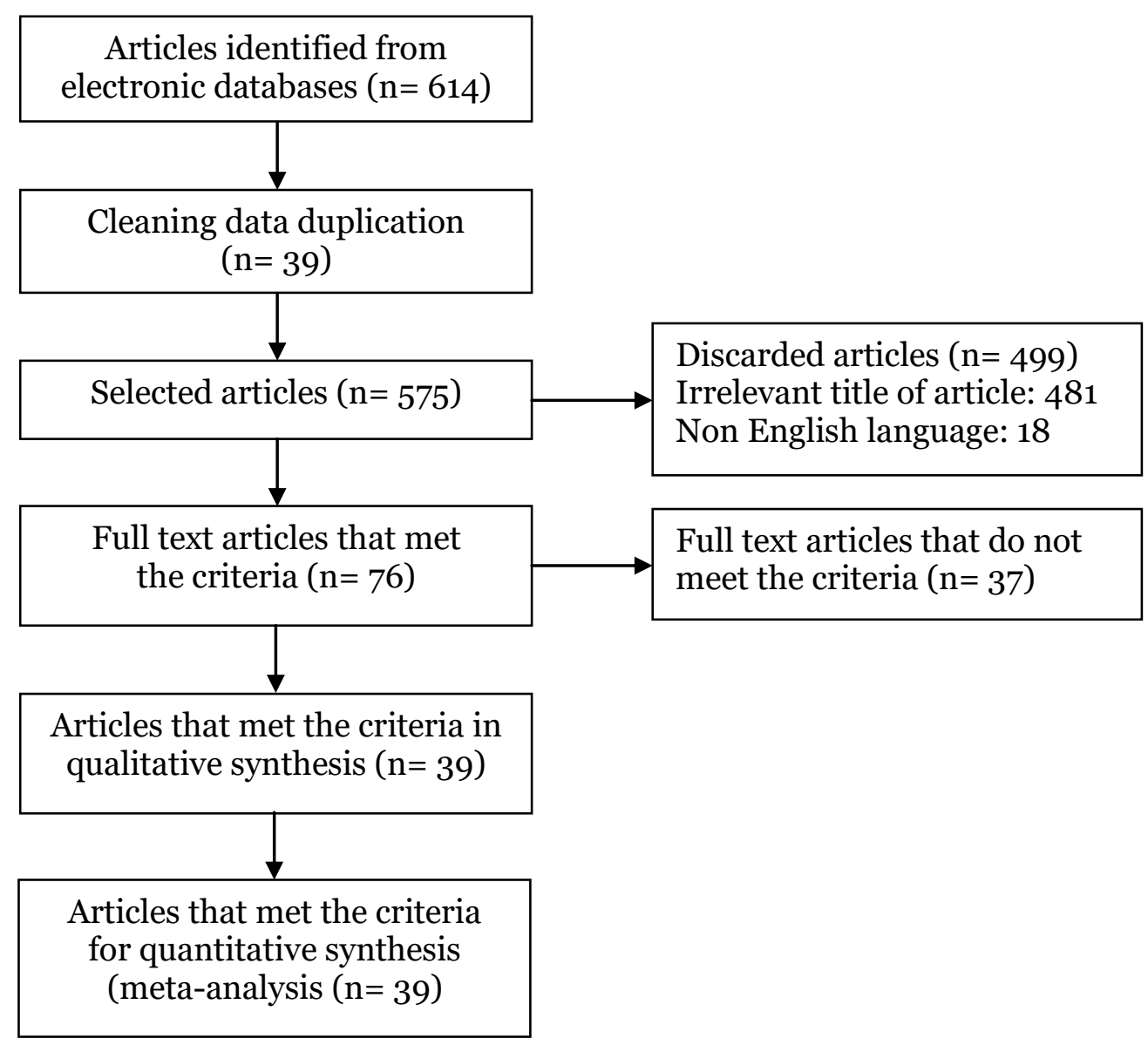

United States, 8 studies) and Europe (Slovenia, 1 study).

Figure 1. Flowchart of the review process

\section{Dispareunia}

Table 1 shows reported the effect of hypnosis on dispareunia from previous studies.

\section{Table 1. Effects of hypnosis on dispareunia}

\begin{tabular}{lcccc}
\hline \multicolumn{1}{c}{ Author (year) } & Country & aOR & 95\%CI & p \\
\hline Barton et al. (2019) & USA & 4.44 & $2.35-8.39$ & $<0.001$ \\
Cieslak et al. (2016) & USA & 3.29 & $0.12-89.81$ & 0.480 \\
Elkins et al. (2008) & USA & 32.11 & $11.79-87.47$ & $<0.001$ \\
Elkins et al. (2013) & USA & 3.02 & $0.12-74.51$ & 0.500 \\
Elkins et al. (2014) & USA & 9.00 & $0.10-831.78$ & 0.340 \\
Johnson et al. (2016) & USA & 2.18 & $1.44-3.30$ & 0.0002 \\
Kandiba \& Binik (2003) & Canada & 9.00 & $0.10-831.78$ & 0.340 \\
Pukall et al. (2007) & USA & 1.31 & $0.31-5.48$ & 0.720 \\
Roberts et al. (2017) & USA & 9.00 & $0.10-831.78$ & 0.340 \\
Starc (2019) & Slovenia & 9.00 & $0.10-831.78$ & 0.340
\end{tabular}

\section{b. Forest plot}

Figure 2 shows the results of a meta-analysis
Table 1 showed that hypnosis was associated with dispareunia. 
Kumalasari et al./ Hypnosis and Dyspareunia

dispareunia by 3.55 times higher compared to no therapy $(\mathrm{OR}=3.55 ; 95 \% \mathrm{CI}=2.63$ to $4.79 ; \mathrm{p}=0.001)$. Heterogeneity $\left(\mathrm{I}^{2}\right)=67 \%$

\begin{tabular}{|c|c|c|c|c|c|}
\hline \multirow[b]{2}{*}{ Stucty or Subgroup } & \multicolumn{2}{|c|}{ Hipnosis } & \multicolumn{2}{|c|}{ Tanpa Hipnosis } & \multirow[b]{2}{*}{ Weight } \\
\hline & Events & Total & Events & Total & \\
\hline Barton et al (2019) & 59 & 87 & 28 & 87 & $19.8 \%$ \\
\hline Cieslak et al (2016) & 11 & 11 & 10 & 11 & $1.0 \%$ \\
\hline Elkins et al (2008) & 51 & 60 & 9 & 60 & $3.0 \%$ \\
\hline Elkins et al (2013) & 187 & 187 & 186 & 187 & $1.1 \%$ \\
\hline Elkins et al (2014) & 1 & 1 & 0 & 1 & $0.3 \%$ \\
\hline Johnson et al (2016) & 111 & 187 & 75 & 187 & $66.9 \%$ \\
\hline Kandyba \& Binik (2003) & 1 & 1 & 0 & 1 & $0.3 \%$ \\
\hline Pukall et al (2007) & 8 & 15 & 7 & 15 & $7.2 \%$ \\
\hline Roberts et al (2017) & 1 & 1 & 0 & 1 & $0.3 \%$ \\
\hline Starc (2019) & 1 & 1 & 0 & 1 & $0.3 \%$ \\
\hline Total (95\% Cl) & & 551 & & 551 & $100.0 \%$ \\
\hline Total events & 431 & & 315 & & \\
\hline
\end{tabular}

Test for overall effect: $Z=8.28$ ( $P<0.00001$ )

which indicated heterogeneous data distribution (random effect model).

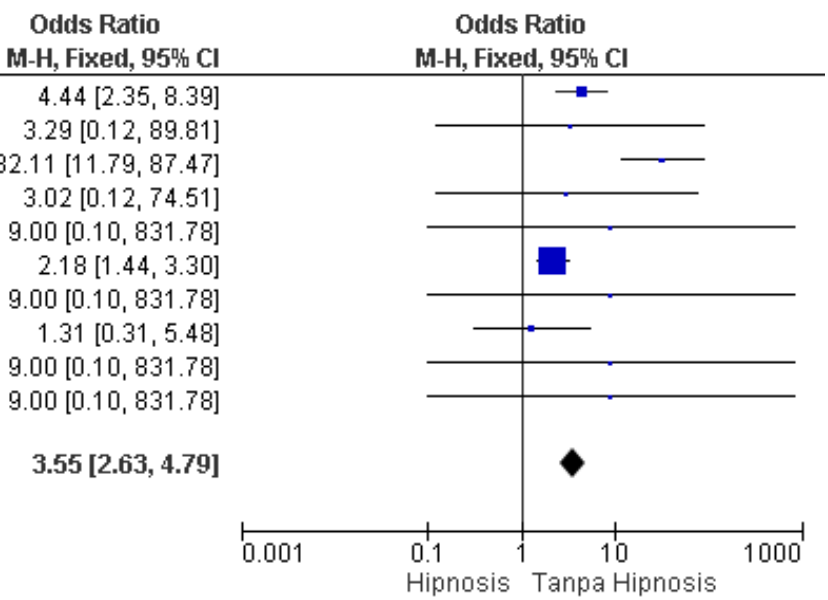

Odds Ratio Odds Ratio

$4.44[2.35,8.39]$

$3.29[0.12,89.81]$

3.02 $[0.12 .74 .51]$

$9.00[0.10,831.78]$

$2.18[1.44,3.30]$

$9.00[0.10,831.78]$

$1.31[0.31,5.48]$

$9.00[0.10,831.78]$

$9.00[0.10,831.78]$

$3.55[2.63,4.79]$

\section{Figure 2. Forest plot of the effect of hypnosis and pain during intercourse}

\section{c. Funnel plot}

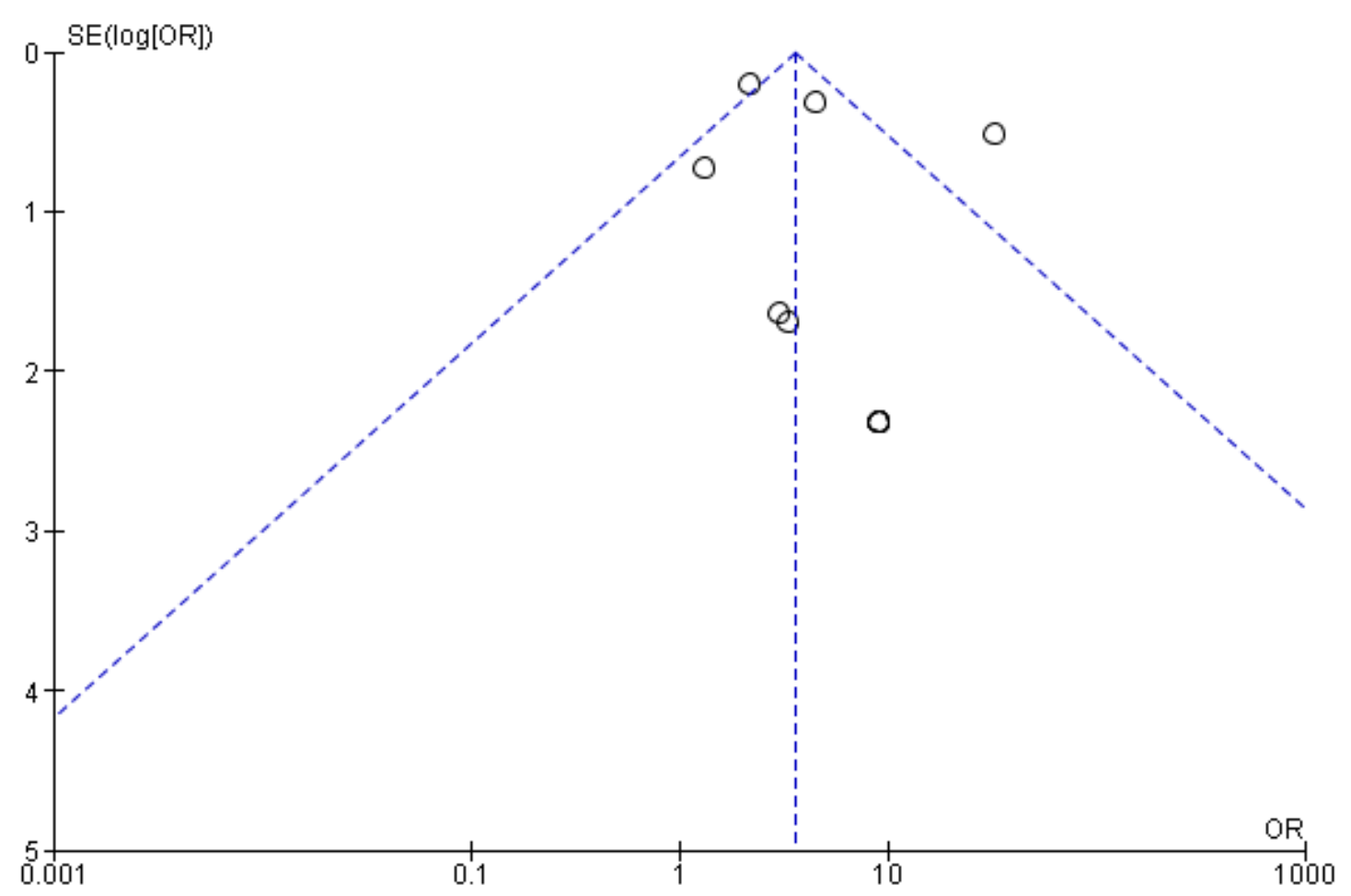

Figure 3. Funnel plots hypnosis and pain during sexual activity

Figure 3 shows that there is a publication bias which is indicated by an asymmetrical shape on the graph, where there are 3 plots on the right and 4 plots on the left. The right and left plots have a standard error between $\mathrm{o}$ and 2. The bias can also be seen from the imbalance of the distance between the studies on both sides, in this graph the plot on the right is more distant than the plot on the left. 
Kumalasari et al./ Hypnosis and Dyspareunia

2. The intensity of pain

effect of hypnosis in women with pain

Table 2 shows 5 studies that reported the intensity disorder during sexual activity.

Table 2. Effects of hypnosis on pain intensity

\begin{tabular}{lcccc}
\hline \multicolumn{1}{c}{ Author (year) } & Country & aOR & $\mathbf{9 5 \% C I}$ & p \\
\hline Barton et al. (2019) & USA & 4.44 & $2.35-8.39$ & $<0.001$ \\
Cieslak et al. (2016) & USA & 3.29 & $0.12-89.81$ & 0.480 \\
Elkins et al. (2013) & USA & 3.02 & $0.12-74.51$ & 0.500 \\
Johnson et al. (2016) & USA & 2.18 & $1.44-3.30$ & 0.002 \\
Pukall et al. (2007) & USA & 1.31 & $0.31-5.48$ & 0.720 \\
\hline
\end{tabular}

\section{b. Forest plot}

Figure 5 shows the results of a meta-analysis of the impact of hypnosis in women with complaints of sexual arousal. Forest plot shows that hypnosis can reduce pain intensity during sexual intercourse by 2.39 times higher compared to no therapy $(\mathrm{OR}=3.55$; 95\% CI= 1.96 to $2.82 ; \mathrm{p}=0.006)$. Heterogeneity $\left(\mathrm{I}^{2}\right)=72 \%$ which indicated heterogeneous data distribution (random effect model).

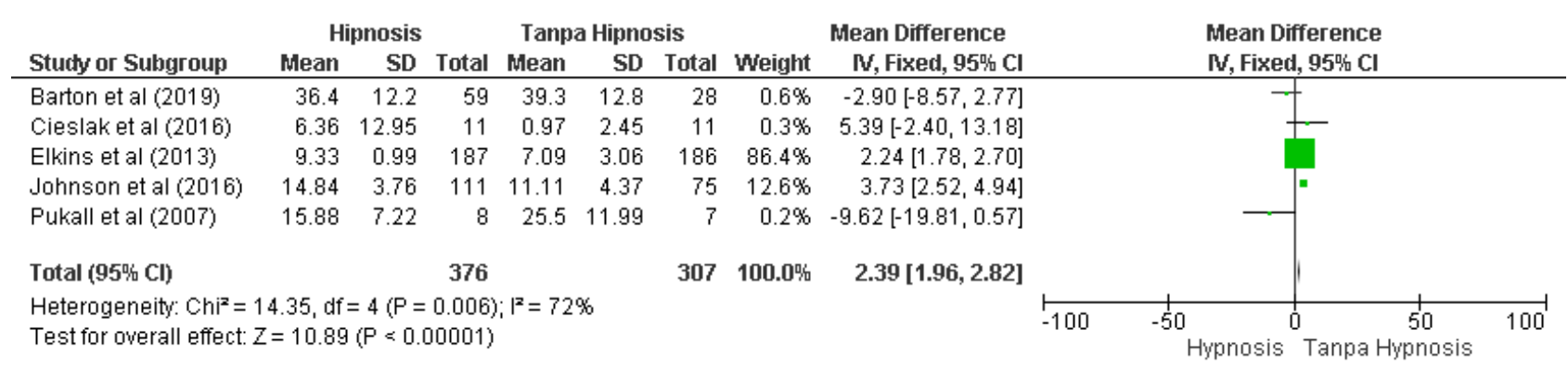

Figure 5. Forest plot of the effect of hypnosis and pain intensity

\section{c. Funnel plot}

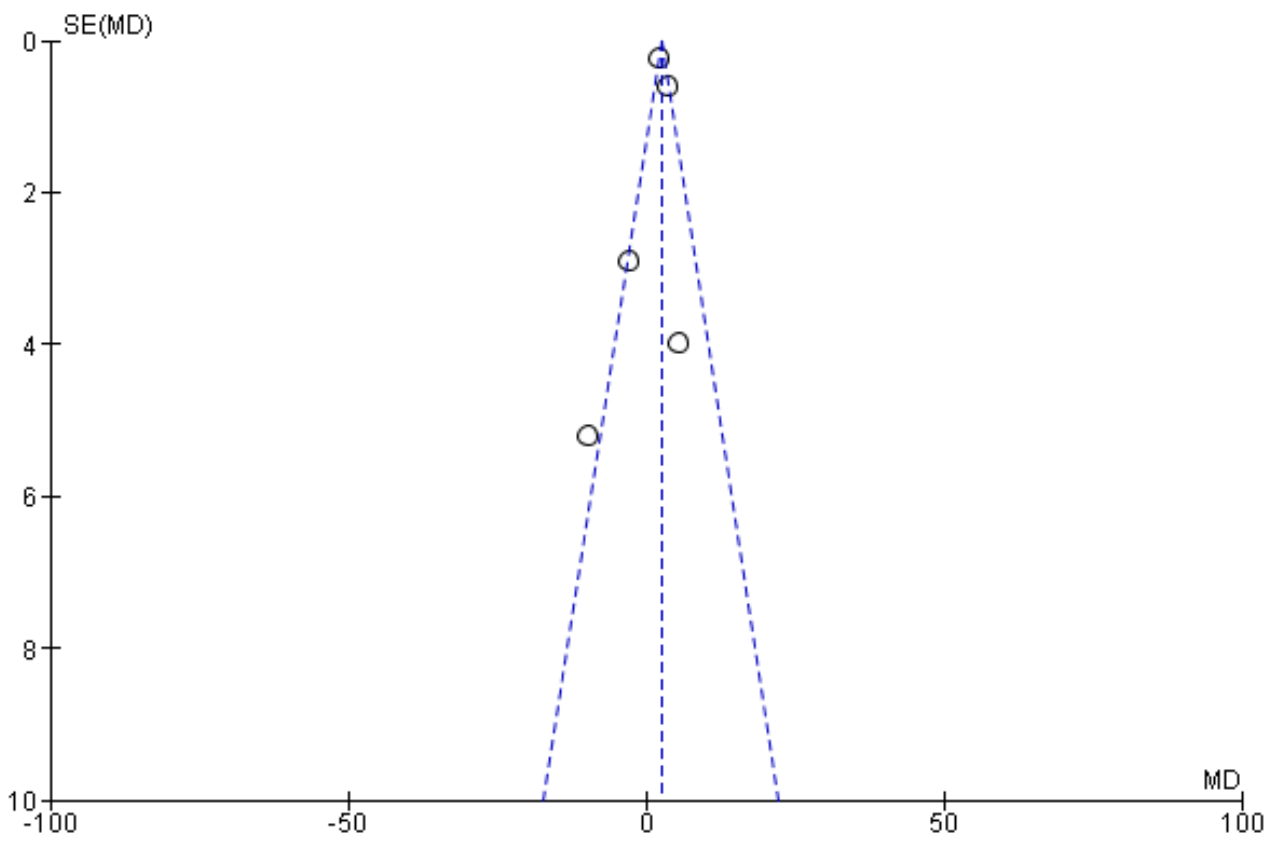

Figure 6. Funnel plots hypnosis and pain intensity 
Figure 6 shows that there is a publication bias which is represented by an asymmetrical shape on the graph, where there are 2 plots on the right and 3 plots on the left. The right and left plots have a standard error between $o$ and 4 . The bias can also be seen from the imbalance of the distance between the studies on both sides, in this graph the plot on the left is more distant than the plot on the right.

\section{DISCUSSION}

Based on the results of the meta-analysis, it showed that hypnosis can reduce the level of pain during sexual activity by 3.55 times higher compared to not providing therapy. In addition, hypnosis can reduce the intensity of pain by 2.39 times higher compared to not providing therapy. According to Margolis (2003), 40\% of women experience sexual dysfunction during their married life, where $1 / 3$ of them experience lack of sexual desire, and 1/4 suffer due to inexperience of orgasm. Research done by Hilz shows that nearly $43 \%$ of women and $31 \%$ of men in America suffer from sexual dysfunction. A random population survey in urban Asia shows that more than 20\% of men and $30 \%$ of women have complained about at least one aspect of their sexual relationships (Nichols, 2005).

Ghaderi (2019) conducted a study for women with dyspareunia complaints, the aim of this randomized controlled trial was to evaluate the effect of pelvic floor rehabilitation techniques on dyspareunia. Of the 84 women assessed eligible to participate in the study, 64 women with dyspareunia were randomized into two groups: the experimental group $(n=32)$ received electrotherapy, manual therapy, and PFM exercises and the control group $(n=32)$ was not treated. Evaluations of PFM strength and endurance, sexual function, and pain were performed immediately before and after 3 months of treatment and at 3 months of follow-up. The results obtained in this study revealed that the changes between groups showed a significant increase in the experimental group compared to the control group. The mean difference in PFM strength (according to the Oxford scale of 0-5) between groups was 2.01 and the mean difference in endurance was 6.26 seconds. The mean difference in the Women's Sexual Function Index score (scores range from 2 to 95) was 51.05, and the mean difference in the VAS score was 7.32. All changes were statistically significant $(\mathrm{p}<0.050)$.

Eva (2016) conducted a study examining the relationship between first experiences of sexual activity/tampon insertion and later experiences of vulvar pain. The study was based on questionnaire data from 1.259 Swedish high school students, aged 18 to 22 years old. The study showed that 592 women reported current vulvar pain. Vulvar pain is currently associated with first-time sexual activity (pain, negative experiences, fighting desire) and with pain with tampon placement. First-time experiences also relate to the temporal aspects of vulvar pain present during vaginal intercourse (at the beginning, after a while, during and after). The implications of first-time sexual activity for future vulvar pain symptoms were also discussed in the results of this study.

Smith et al. (2019) recommend a multidisciplinary therapy program for provoked vestibulodynia (PVD) cases, and very few have evaluated its success. This study examined the trajectory of women's symptoms over time, as well as baseline demographic, psychosocial and pain characteristics as predictors/moderators of pain and sexual distress while attending clinic treatments using multidisciplinary methods simultaneously. 
Attachment theory can provide a useful framework for understanding why women experience painful in sexual experiences. Anxiety and avoidance are the two main dimensions of insecurity felt by women. Based on these two dimensions, it can be derived as follows: (1) safe attachment, which is a combination of low anxiety and low avoidance, (2) fear attachment, which is a combination of high anxiety and high avoidance, (3) busy attachment, which is a combination of high anxiety and low avoidance, (4) rejecting attachment, which is a combination of high avoidance and low anxiety (Brennan, Clark, \& Shaver, 1998).

The limitations of this study were (1) Based on the 10 articles reviewed, all of them did not include primary data. (2) There was a publication bias shown in the funnel plot on the relationship between hypnosis and stress. (3) There was language bias because in this study only articles published in English were not included in the analysis process. (4) There was search bias because in this study it only used 4 databases (Google Scholar, Springer Link, PubMed, and Science Direct) so that it ignored other search sources. (5) Among the 10 articles analyzed, none of them came from the continent of Africa, Asia, Australia. (6) In the process of identifying articles, there were many articles that were not full text.

The conclusion of this study is hypnosis can reduce the pain level during sexual activity by 3.55 times higher compared to no therapy. The statistical results show the value of $\mathrm{OR}=3.55 ; 95 \% \mathrm{CI}=0.63$ to 4.79 . Hypnosis can also reduce the pain intensity by 2.39 times higher compared to not providing therapy. The statistical results show the value $\mathrm{OR}=2.39 ; 95 \% \mathrm{CI}=1.96$ to 2.82 .

The results of this study support the results the other study which states that hypnosis treatment can be used to improve sexual dysfunction, as well as get better sexual satisfaction and marital satisfaction. This is very important because hypnosis is more effective and efficient in helping complaints of sexual dysfunction, sexual dissatisfaction and marital dissatisfaction.

\section{AUTHOR CONTRIBUTION}

Kumalasari is the main writer who selected topics, searched, and collected study data; Didik Gunawan Tamtomo played a role in reviewing articles; Hanung Prasetya helped the data analysis process.

\section{CONFLICT OF INTEREST}

The author stated that this study was conducted without any commercial and financial relationships which resulted in a potential conflict of interest in it.

\section{FUNDING AND SPONSORSHIP}

This study used personal fund.

\section{ACKNOWLEDGEMENT}

None.

\section{REFERENCE}

Andromeda NP (2015). Berjuang dan terus bertahan: Studi kasus kepuasan perkawinan pada isteri sebagai tulang punggung keluarga. Seminar Psikologi \& Kemanusiaan. 557-563. Available at: http://mpsi.umm.ac.id/files/file/557-563 zzAndromeda.pdf.

Breslin ET, Lucas VA (2003). Women's health nursing toward evidence based practice. Missouri: Elsevier.

Brennan KA, Clark CL, Shaver PR (1998). Self-report measurement of adult attachment: an Integrative Overview. In J. A. Simpson \& W. S. Rholes (Eds.), Attachment theory and close relationships. New York: Guilford Press. 
Elmerstig, Eva; Thomtén, Johanna (2016). Vulvar pain-associations between first-time vaginal intercourse, tampon insertion, and later experiences of pain. Journal of Sex \& Marital Therapy, 42: 8,707-720. DOI: $10.1080 / 0-$ 092623X.2015.1113589.

Ghaderi F, Bastani P, Hajebrahimi S, Jafarabadi MA, Berghmans B (2019). Pelvic floor rehabilitation in the treatment of women with dyspareunia: A randomized controlled clinical trial. International urogynecology journal, 3o(11): 1849-1855. https://doi.org/10.1007/s00192-019-04019-3.

Halvorsen JG, Metz ME (1991). Sexual Dysfunction, Part I: Classification, Etiology, and Pathogenesis. Am Board Faro Pract 1991; 5:51-61
Margolis S (2003). Sexual Dysfunction. <http://www.Healthatoz.com/health atoz/Atoz/dc/caz/repr/sexi/spandex. html>

Nichols MP (2005). Concurrent discriminant validity of the Kansas marital satisfaction scale. Journal of Marriage and the Family, 48(2):381-387.

ScienceBeebe KR (2014). Hypnotherapy for Labor and Birth, Nursing for Women's Health. Elsevier Masson SAS, 18(1): 48-59. doi: 10.1111/1751486X.12093.

Vaziri SH, Lotfi-Kashani F, Hosseinian S, Bahram-ghaffari S (2010) Sexual selfefficacy and marital satisfaction. Thought and Behavior Applied Psychology. 4(16): 75-81. 